This is a pre-final version of the manuscript eventually published as:

Ingrid Konrad, Massimo Burattin, Carlo Cecchetto, Francesca Foppolo, Adrian Staub and Caterina Donati, Avoiding Gaps in Romance: Evidence from Italian and French for a Structural Parsing Principle. Syntax, Wiley-Blackwell, 2021, pp.191223. 
Title

\section{Avoiding gaps in Romance: Evidence for a structural parsing principle from Italian and French.}

\section{Abstract}

Existing evidence suggests that the parser avoids positing a movement dependency if the grammar allows it. By investigating the processing of two syntactic ambiguities that have not been previously studied, we provide more conclusive evidence for this parsing bias in two Romance languages: French and Italian. In two acceptability judgment experiments and two self-paced reading studies, we found that sentences that involved a filler-gap dependency (indirect questions in Italian and free relatives in French) were dispreferred compared to sentences involving the same lexical material but no filler-gap dependency (declarative complement clauses in both languages). Crucially, the filler-gap dependency was not dispreferred when there was no available competitor. We discuss these results as also relevant for syntactic theory and for the questionable status of Merge over Move as a grammatical principle.

\section{Processing GAPS}

Movement dependencies have been a central topic in sentence processing research since pioneering work by Fodor 1978 and Clifton and Frazier 1989, among others. Most of this psycholinguistic research has investigated the process of searching for the gap once a moved element is encountered during incremental processing, suggesting that an active search for a gap is immediately initiated (the Active Filler Strategy; Clifton \& Frazier 1989). The Active Filler Strategy is also captured by the second clause of the Minimal Chain Principle (De Vincenzi 1991). 
Avoid postulating unnecessary chain members at surface structure, but do not delay required chain members.

The first clause of the Minimal Chain Principle states that chains (i.e. filler-gap dependencies) should not be posited by the parser unless this cannot be avoided given the rules of the grammar, while the second clause states that the sentence should be parsed by assuming that the chain, in case it must be posited, is as short as possible. The ultimate justification for these parsing principles rests on the parser's need to optimize memory resources: because holding unstructured material in short-term memory is taxing, the system employs strategies that minimize processing costs during sentence processing, so unsaturated fillers are avoided as much as possible.

An illustration of the second clause of the Minimal Chain Principle is the processing difficulty that would be encountered at the verb eat in (2), which suggests that the processor initially computes the odd interpretation on which the family has eaten a dog (Pickering \& Traxler 1996; Stowe 1986). When encountering a wh-element, the parser recognizes that a chain is required and initiates the search for a gap, which is first posited after the verb because this is the first available position for a gap given the grammar of English.

(2) Which dog did the family eat happily with ?

Despite much converging evidence for the second clause of the Minimal Chain Principle, few attempts have been made to substantiate its first clause, according to which a construction with a gap should be avoided if a construction without a gap is available during incremental parsing.

In this paper, we contribute to this debate by testing two minimally different structures 
which differ only in the presence/absence of a chain. Adopting a psycholinguistic perspective, we address the question of whether the postulation of a chain is dispreferred by the parser, as prescribed by the first clause of the Minimal Chain Principle. Building on the fact that notions such as efficiency of computation and economy are central notions in minimalist theory of syntax as well, psycholinguistic evidence in favour of the first clause of the Minimal Chain Principle could also contribute to the theoretical debate, as we will discuss in the concluding session.

The article is organized as follows. We first discuss a recent study by Staub, Foppolo, Donati, and Cecchetto 2018 on the processing of temporarily ambiguous structures involving a relative clause or a complement clause. We outline the results of this study, which provide clear evidence for structural principles guiding incremental processing of this ambiguity but are not conclusive regarding the specific structural principle at play $(\S 2)$. We then present and discuss four experiments run in Italian and French, all involving temporarily ambiguous constructions that are compatible with continuations that either do or do not involve a filler-gap dependency (§3-6). We conclude that the results of these experiments provide clear and unambiguous evidence that incremental processing avoids positing a gap whenever it can. We discuss theoretical implications of this conclusion in the general discussion $(§ 7)$.

\section{On some non-conclusive evidence for the first clause of the Minimal Chain Principle}

As mentioned above, few attempts have been made to support the first clause of Minimal Chain Principle (1), according to which a construction with a gap should be avoided if a construction without a gap is available during incremental parsing. For example, according to this

principle, the parser would prefer continuation (a) over (b) when encountering the fragment in (3): 
(3) The announcement that the president is considering...

a. an intervention will alarm the citizens.

b. _ will alarm the citizens.

In their recent work, Staub et al. (2018) investigated the processing of the syntactic ambiguity in strings such as (3) where the that-clause can be either the clausal complement (CC; as in $3 \mathrm{a}$ above) of the noun or an object relative clause ( $\mathrm{RC}$; as in $3 \mathrm{~b}$ above) involving the presence of a gap, i.e., a movement trace in the object position of the verb consider. Three eyetrackingduring-reading experiments showed a processing advantage for $\mathrm{CC}$ continuations. Importantly, this advantage was not modulated by the specific frequency bias of the head noun to appear with a $\mathrm{CC}$ or an $\mathrm{RC}$ construction, thus providing evidence that this parsing preference is attributable to structural parsing principles, which are ultimately based on syntactic complexity, rather than to frequency-based heuristics. This relative-clause avoidance was interpreted by Staub et al. as a general strategy of gap-avoidance, in line with the first clause of the Minimal Chain Principle.

However, a limitation of Staub et al.'s study was the fact that the two structures tested (CC vs. RC) arguably differ in other respects in addition to the presence versus absence of a gap. In traditional X-bar terms, the two structures differ in the attachment site of the critical clause: The $\mathrm{CC}$ is directly attached to the first projection of the noun (4), while the RC, being an adjunct, requires an extra node in the projection of the noun, as shown in (5).

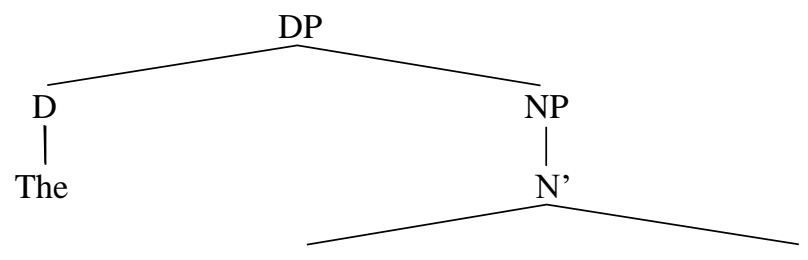




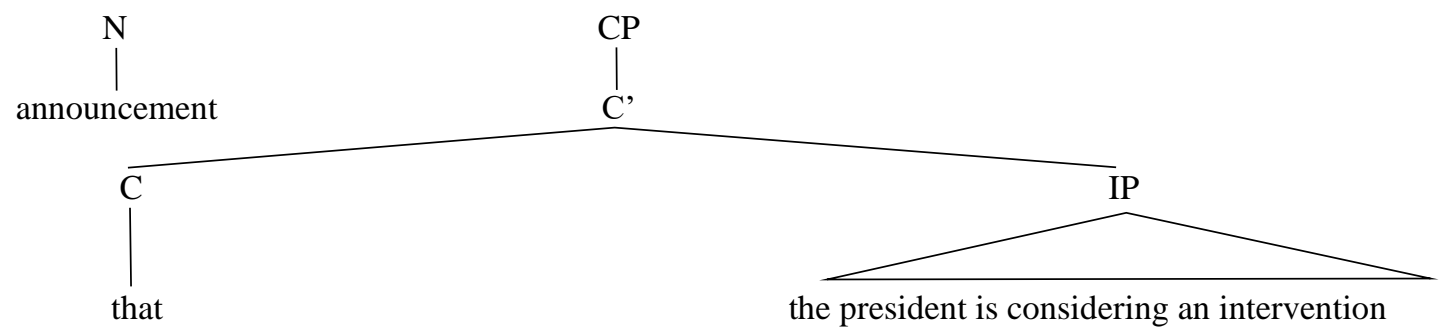

(5)

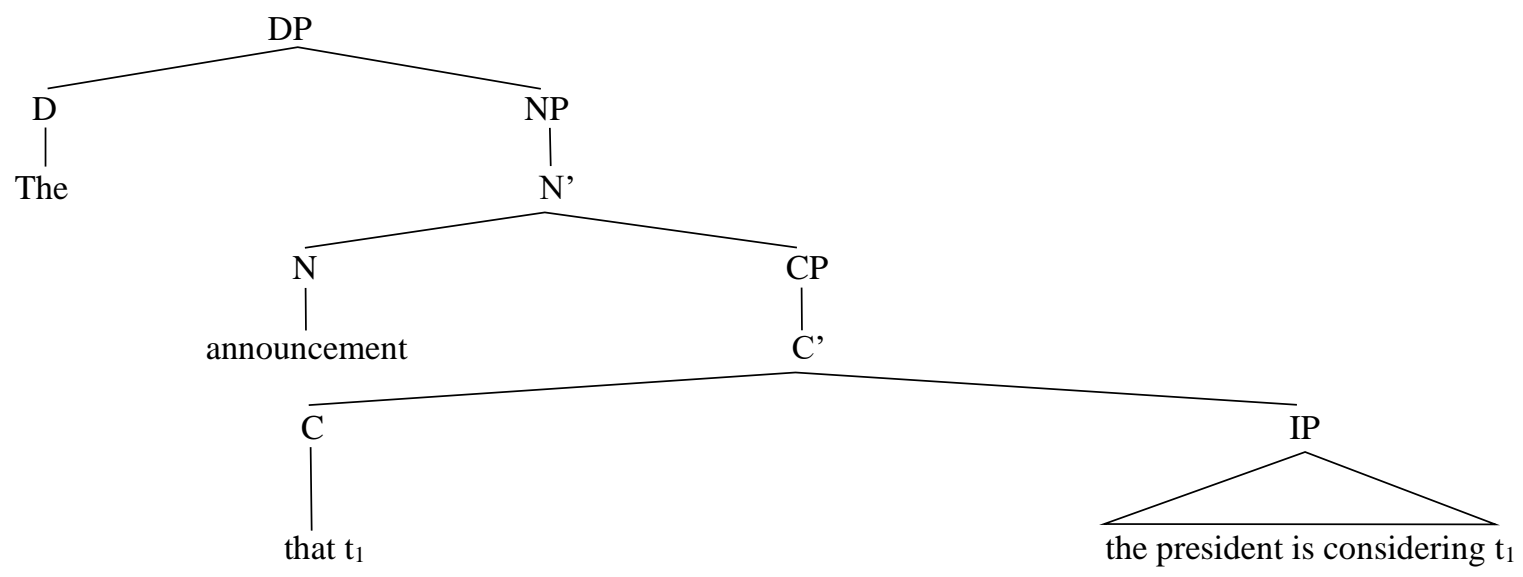

If the representations in (4) and (5) are correct, the preference observed by Staub et al. for a CC over a RC continuation might also be accounted for in terms of another parsing principle, such as Minimal Attachment (Frazier 1978, 1987). The Minimal Attachment Principle states that the parser prefers the structure that requires the minimal number of syntactic nodes to be added to the developing syntactic representation of the sentence. For example, the Minimal Attachment principle explains why in on-line tasks the continuation in (6a) is preferred to the continuation in (6b) (Frazier and Rayner 1982). In (6a) the inheritance is the direct object of claim (hence directly attached to it), while in (6b) the inheritance is the subject of an additional embedded clause. The latter analysis requires positing additional structure that is not required on the former analysis. 
(6) The lawyers think his second wife will claim ...

a. the inheritance.

b. the inheritance belongs to her.

We note that the representation in (5) is based on an older syntactic formalism. For example, it is not compatible with Minimalist approaches to phrase structure stemming from Chomsky (1995), as it contains a vacuous projection above the noun announcement, and vacuous projections are not allowed in the simplified apparatus of bare phrase structure theory. However, the Minimal Attachment principle suggests that, if a grammar allows a choice, the parse that postulates a complementation configuration is preferred over a parse that postulates an adjunction configuration. This parsing preference for complementation over adjunction can be implemented in any phrase structure formalism that maintains a difference between argument and adjuncts. A way to represent adjunction in bare phrase structure is through Pair Merge (as opposed to Set Merge). Adopting this representation, CCs would involve Set-Merge (cf. 7) while RCs would involve Pair-Merge (cf. 8):

(7) $\quad$ announcement, $\{$ that the president is considering an intervention $\}\}$

(8) < announcement, \{ that the president is considering _ $\}>$

An updated version of the Minimal Attachment principle would argue that the representation in (7) is preferred over the representation in (8) not because (7) contains fewer nodes than (8), but because (7) involves Set Merge (i.e., complementation) while (8) involves Pair Merge (i.e., adjunction). 
In any event, the Minimal Attachment explanation for the preference of RCs over CCs in (3) is controversial. For one thing, some authors (Arsenijević 2009) have argued that at an abstract level CCs should be analyzed as a special type of RCs since both involve operator movement. However, de Cuba (2017) offers a criticism of this claim. Also, Staub's et al. experimental results are at odds with this hypothesis, since they indicate that CCs and RCs are parsed differently and hence point at a structural difference between the two.

The Minimal Attachment explanation for the pattern in (3) is also questioned by (semantic) accounts that take clausal "complements" of nouns not to be complements, since they are taken to combine with the noun by Predicate Modification rather than through Function Application (cf. Stowell 1981 for an early claim and Kratzer 2006 and Moulton 2009 for a comprehensive semantic account). If both CCs and RCs involve Predicate Modification, Minimal Attachment would not distinguish between them. A more general challenge to the Minimal Attachment explanation for the facts in (3) is the claim that nouns never take complements (cf. Kayne 2008 for an early proposal, and Adger 2013, and Cecchetto \& Donati 2015 for recent works containing extensive motivation for this claim). If the distinction between adjunction and complementation cannot be exported to the nominal domain, the Minimal Chain Principle has nothing to say on the preference for CCs over RCs to begin with. Still, we think that the Minimal Attachment explanation cannot be entirely excluded based on the experimental evidence available so far, and thus it remains an available account for the preference for CCs reported by Staub and colleagues.

\section{Overview of the experimental studies}


In this paper we aim to provide new evidence to disentangle Minimal Attachment from the first clause of the Minimal Chain Principle. We will do so by investigating temporarily ambiguous structures in Italian and in French that are resolved with either the presence or the absence of a filler-gap dependency. In Italian, the element che can introduce a declarative complement clause or an indirect question. ${ }^{1}$ This makes the segment in (9) temporarily compatible with a declarative complement clause that contains no gap, as in (9a), and with an indirect question that involves a gap in the position of the direct object following the second verb, as in (9b).

(9) Gli studenti hanno capito che...

'The students understood that/what'

(a) fare gli esami è difficile.

'taking exams is difficult'

(b) fare _ agli esami difficili.

'to do _ at difficult exams'

(a) 'The students understood that taking exams is difficult'

(b) 'The students understood what to do at difficult exams'

In both (9a) and (9b) the continuation is a complement to the main verb, so the difference between complementation and adjunction is not at play here, unlike in the contrast that is the focus of Staub's et al. study.

Similarly, in French, the element ce que can introduce a declarative complement clause as in (10a) or a free relative as in (10b). This makes the segment (10) temporarily compatible with a

\footnotetext{
${ }^{1}$ On the nature and the status of 'che' in Italian, see Manzini \& Savoia 2003 and Rizzi 2019, among others.
} 
construction that contains no gap, as in (10a), and with a construction that involves a gap in the position of the direct object of the embedded verb, as in (10b). ${ }^{2}$

(10) Yasmina s'habitue à ce que...

'Yasmina gets used to the fact that/what'

(a) sa mère regarde la télé chaque matin.

'her mother watches TV every morning'

(b) sa mère regarde _ chaque matin.

'her mother watches _ every morning'

(a) 'Yasmina gets used to the fact that her mother watches TV every morning'

(b) 'Yasmina gets used to what her mother watches every morning'

In this case also the two continuations are both complement clauses selected by the main verb, and Minimal Attachment (in terms of number of nodes or type of merge) does not distinguish between the two.

If the parser is guided by a parsing principle on the lines of the first clause of the Minimal Chain Principle, by which a construction with a gap should be avoided whenever an alternative construction without a gap is available, then the straightforward prediction is that the declarative complement clause continuations in both Italian and French should be preferred, since they do not involve a filler-gap dependency. We tested this prediction in four experiments: an acceptability judgment experiment and a self-paced reading experiments in each of the target languages. The

\footnotetext{
2 Relative clauses introduced by 'ce que' in French are in fact analysed as light-headed relative clauses, the demonstrative 'ce' being the light head and 'que' being the complementizer. See Konrad 2019a and Konrad 2019b for a detailed syntactic analysis.
} 
acceptability judgment experiments conducted in the two languages were similar in their design; the self-paced reading experiments exploited the same material used in the judgment studies in order to locate the region of difficulty in the sentences and further explain the differences across conditions observed in the off-line judgments.

As discussed above, our intent was to test whether Italian and French participants showed a preference for the construction with no gap when the preceding verb allowed for such a construction. To this end, we selected a series of verbs (like capire in Italian, 'to understand', or s'habituer in French, 'to get used to') that admit a continuation with no gap (a declarative clause in both languages) and a continuation involving a gap, such as an indirect question in Italian or a free relative in French. To determine with greater certainty that any difficulty in the sentences with a gap resulted from the initial adoption of an available continuation without a gap, we created a control condition that involves a different matrix verb. An example of these control sentences is provided in (11) for Italian and (12) for French. Although the material following the critical

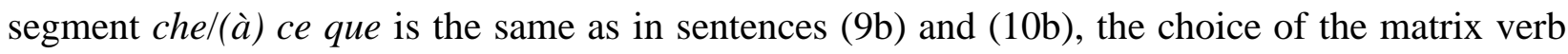
determines that a continuation without a gap is ruled out earlier than in (9b) and (10b) (for example, at the word fare in Italian in 11 and at the word ce que in French in 12).

(11) Gli studenti hanno chiesto che fare _ agli esami difficili.

'The students asked (*that)/what to do _ at difficult exams'

(12) Yasmina voit ce que sa mère regarde _ chaque matin. 'Yasmina overlooks (*that)/what her mother watches _ every morning'

Because an analysis without a gap is ruled out at an early stage of incremental processing of these sentences, we did not expect any difficulty at the gap position. 


\section{Experiment 1. Gaps after che in Italian: Acceptability judgments}

The first experiment is an acceptability judgment study conducted in Italian. We compared sentences like (9a-b), which contain che and are temporarily ambiguous between an indirect question analysis that involves a filler-gap dependency and a declarative complement analysis that does not. We also included sentences like (11), in which a declarative complement continuation is ruled out. We expected a garden-path effect when the verb can select a declarative complement clause, but is ultimately disambiguated toward the indirect question analysis. The cost of this garden path is predicted to be reflected in lower acceptability ratings in this condition.

\subsection{Methods}

\subsubsection{Participants}

Sixty-seven adult Italian participants volunteered to participate after being recruited via Facebook or other social networks across Italy. They were between 18 and 72 years of age (Mean =36). We asked participants to provide some personal information before taking the test, including their regional origin, as well as the regional Italian variant they speak. On this questionnaire, 34 stated that they were born and raised in the North of Italy, and 33 in the Center-South of the peninsula.

\subsubsection{Materials}

Materials included 24 experimental items in the three experimental conditions described above and repeated in (13) for convenience, and 24 filler items, presented in an individually randomized order for each participant after three practice items. Henceforth we refer to conditions (a-c) as amb.noGap, amb.Gap, and unamb.Gap, respectively. Filler items ranged from being fully 
grammatical to fully ungrammatical, and included sequence-of-tense violations, unlicensed negative polarity items and island violations.

(13) a. Gli studenti hanno capito che fare gli esami è difficile. (amb.noGap)

'The students understood that taking exams is difficult'

b. Gli studenti hanno capito che fare agli esami difficili. (amb.Gap)

'The students understood what to do for difficult exams'

c. Gli studenti hanno chiesto che fare agli esami difficili. (unamb.Gap)

'The students asked what to do for difficult exams'

As detailed above, che introduces a declarative complement clause in the amb.noGap condition, and an indirect question in the other conditions. The unamb.Gap condition is unambiguously interpreted as an indirect question at an earlier point than in amb.Gap, since the former rules out a declarative continuation at the verb following che. However, it is important to note that the verb in the unamb.Gap condition also allows for a simple direct object continuation in which a DP comes directly after the matrix verb (14) or for a non-interrogative complement clause (15). We return to this issue below.

(14) Gli studenti hanno chiesto le chiavi

The students asked (for) the keys

(15) Gli studenti hanno chiesto che venissero consegnate le chiavi

The students asked that (someone) gave (them) the keys

It is also important to mention that in Italian, what-questions can be introduced by at least 
two other forms in addition to bare che: the full form che cosa (lit. 'what thing') and the ellipitical form cosa (lit. 'thing'). The entire paradigm of possibilities is illustrated in (16), all of which are translations of 'What are you saying?'

(16) a. Che cosa dici?

'What thing you say?'

b. Cosa dici?

'Thing you say?'

c. Che dici?

'What you say?'

The variant with bare che that we use in this study is more informal than the other forms. Moreover, it is reported to be used more productively in the Center and the South of Italy, but less frequently than the variants in (16a) and (16b) in the Northern regions. Nonetheless, this variant should not be considered as substandard or dialectal, since it is well attested in written Italian, and even in literary oeuvres. As an example, one of the most famous poems of the Italian literary tradition, Giacomo Leopardi's Canto notturno di un pastore errante dell'Asia, begins with this interrogative element che:

(17) Che fai tu, luna, in ciel? dimmi, che fai,

Silenziosa luna?

'What are you doing, moon, in the sky? Tell me, what are you doing, silent moon?'

The geographical and dialectal information that we collected from participants did not show any 
interaction with the critical effects in our statistical models, so we do not discuss these data further.

\subsubsection{Procedure}

Participants were asked to judge each sentence on a 7 point Likert scale in which 1 meant "not natural at all" and 7 meant "perfectly natural". They were instructed not to judge the content of the sentences, but only to pay attention to their "form". They were also explicitly told not to rely on grammatical rules learned at school, but simply to judge the sentences on the basis of how natural the sentences sounded to them as speakers of Italian. The experiment was implemented and administered on-line on IbexFarm (Drummond 2013) and lasted approximately 15 minutes. A full list of the experimental materials is provided in Appendix A.

\subsection{Results}

The full results are presented in Figure 1. The top panels of this Figure show the distributions of ratings in each condition, on the 1-7 scale, while the bottom panels show the distribution of subject means in each condition. The amb.noGap condition received high ratings overall (mean of 5.54), and the modal response was 7. On the other hand, the two indirect question conditions received much lower mean ratings (2.81 in amb.Gap and 3.16 in unamb.Gap), and the modal response to both conditions was 1 . Fully grammatical filler sentences received high ratings $($ mean $=5.8)$, while ungrammatical fillers received very low ratings $($ mean $=1.9)$.

To evaluate the pattern of responses statistically, we implemented a mixed-effects ordinal regression model with a logit link function, using the $\operatorname{clmm}()$ function in the ordinal package (Christensen 2018). This is a statistical model specifically designed to treat ordinal dependent measures that cannot be assumed to represent an interval scale, as is the case with the Likert scales used in our study. We use treatment contrasts with amb.Gap as the reference level, allowing a direct 
test of the hypothesis that ratings in this condition are lower than in each of the other two. The maximal model that converged included condition as a fixed effect, subjects and items as random intercepts, and random condition slopes for subjects. The analysis revealed that ratings of both amb.noGap and unamb.Gap were significantly higher than ratings of amb.Gap, though the former difference was substantially larger (amb.noGap Estimate $=3.402, \mathrm{SE}=0.214, z=15.888, p<$ .0001 ; unamb.Gap Estimate $=0.481$, Std. Err SE $=0.126, z=3.822, p<.001)$. 

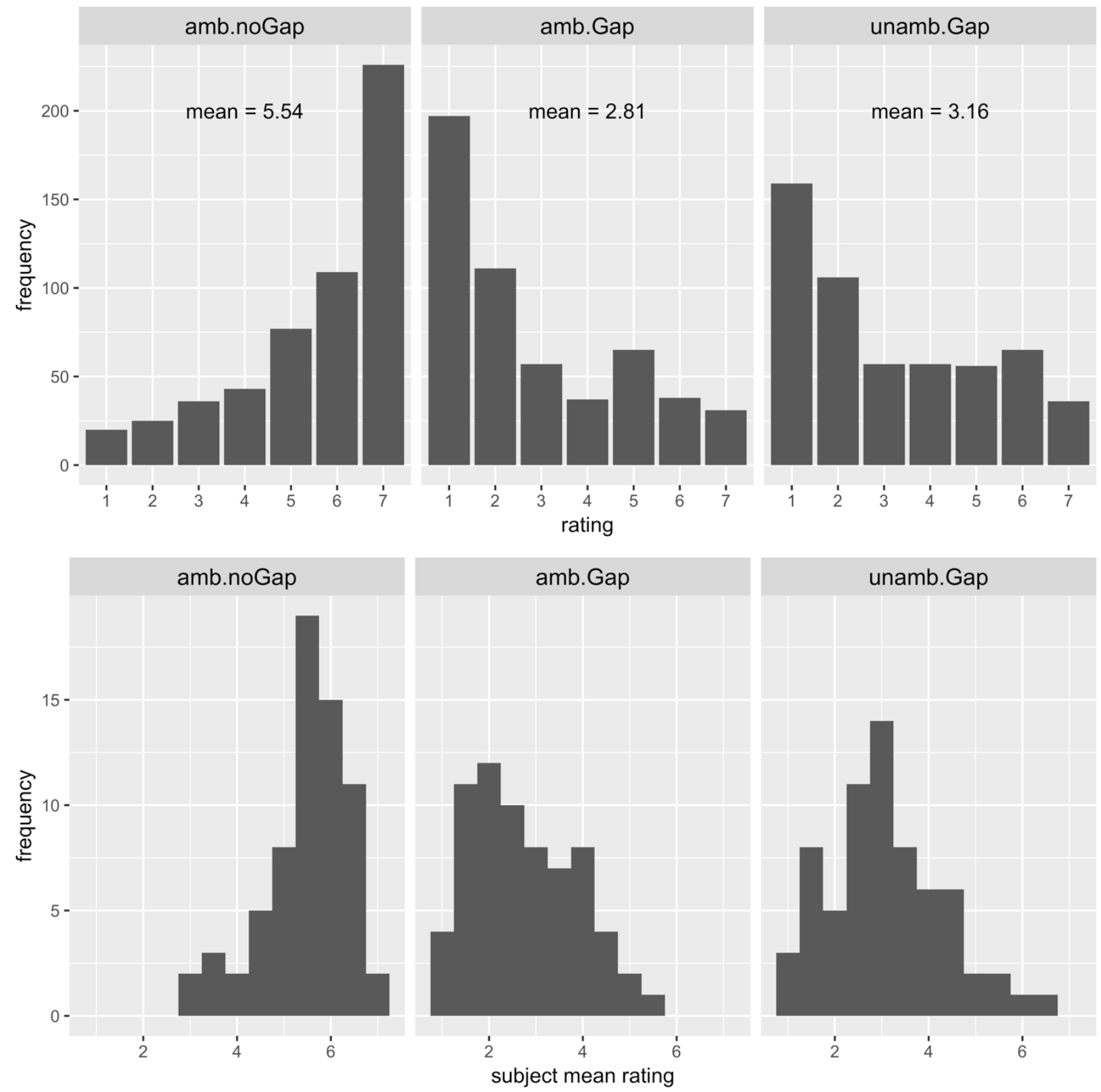

Figure 1. Results of Italian acceptability judgment study. Top panels show distributions of individual ratings in each condition, and bottom panels show distributions of subject means.

\subsection{Discussion}

The results suggest that the temporary availability of a complement clause analysis reduces the ratings of sentences in which an indirect question is introduced by che. The observed pattern 
is consistent with the hypothesis that participants, when reading the amb.Gap sentences, initially adopted the alternative complement clause analysis and only at a later stage were forced to reanalyse the sentence as an indirect question. This reanalysis was not required in the unamb.Gap condition, in which a declarative complement clause continuation was ruled out earlier on.

In principle, the reduced ratings of the amb.Gap condition compared to the amb.noGap condition might depend on the frequency with which the verbs used in our study take a CC or an $\mathrm{RC}$ continuation. A systematic evaluation of this possibility is difficult, as there are no available annotated Italian corpora that allow us to check whether che is more frequent as complementizer than as a fronted $w h$-word, either in general or with specific verbs. This is further complicated by the fact that the use of che alone as a $w h$-word, as exemplified in (16c) might not be well represented in written corpora like the only one available for Italian, which is mostly based on newspapers (ItWaC, Baroni et al. 2009), since this use of che is mostly used in spoken language (with notable exceptions, cf. (17)). However, we addressed this possibility by checking how the mean rating for a particular verb in the amb.Gap condition varies as a function of the verb's mean rating in the amb.noGap condition: given that the same verb is used in both conditions, verb bias should modulate the preference in the two conditions in opposite directions, i.e., high ratings in one condition should be accompanied by low ratings in the other, for each of the verbs. In fact, we only find a mild, and non-significant, correlation between these ratings $(r=-.21$, n.s.). Moreover, any hint of negative correlation seems to be driven by just two of the 20 verbs used, 'leggere' and 'comunicare', which have the highest ratings in the Gap and noGap conditions, respectively. See Appendix C for a plot of the observed relationship.

This analysis suggests that verb-based frequency bias is not the (only) factor affecting the observed judgements. At the same time, we cannot overlook the fact that the unamb.Gap condition also received low ratings, though significantly higher than amb.Gap sentences. These low ratings 
could in principle receive various explanations. A first explanation could be that the low ratings in the unamb.Gap condition are due to a dialectal variation in the acceptability of the che variant of che cosa. However, the bottom right panel of Figure 1 shows no hint of bimodality in the acceptability of this construction, as most participants did not rate the unamb.Gap condition very highly, regardless of their geographical origin. A second possibility is that unamb.Gap sentences receive relatively low ratings because the wh-phrase che cosa is preferred to the informal whphrase che, as shown in (16). Finally, a third possibility is that in the unamb.Gap condition, ratings are reduced because the movement analysis induces a parsing cost even without an initial ambiguity. We further consider these possibilities in the next experiment, which uses self-paced reading to examine incremental processing of these sentences.

\section{Experiment 2. Gaps after che in Italian: Self-Paced Reading}

The second experiment is a self-paced reading study conducted on a separate group of Italian participants using the same materials as in the preceding acceptability judgment experiment. By having participants read the sentences one word at a time, and by recording their reading times at each word, we aimed to locate the point in incremental processing at which difficulty appears in each of the two conditions that received low ratings, amb.Gap and unamb.Gap.

\subsection{Methods}

\subsubsection{Participants}

A separate group of 52 adult Italian adults participated in this study. They were mainly students at the University of [DELETED FOR ANONYMITY] and received course credit for 
participation. They were between 18 and 53 years of age $($ Mean $=22.6)$. As for the acceptability judgment study, prior to completing the experiment the participants were asked to provide some personal information, including their regional origin, as well as the regional variants of Italian they speak. Forty-six declared that they were born and raised in the North of Italy, and 5 in the CenterSouth of the peninsula. One participant was excluded from subsequent analyses as she declared herself to be bilingual, with German as her first language.

\subsubsection{Materials}

The experiment used the same materials as the rating study, including the fillers. The experiment was conducted in one of the labs at the University of [DELETED FOR ANONYMITY] and it was implemented and administered on IbexFarm. Sentences appeared word by word in the center of the screen and participants had to press the spacebar to continue with the following word. Participants were instructed to read the sentences at their normal reading pace for comprehension. No comprehension questions were asked.

\subsection{Results}

For the purposes of analysis, each word's position in the sentence was coded in two ways. In the first analysis, each word's position was coded with respect to che; e.g., the word preceding che was in position -1, and the word following che was in position 1. In the second analysis, each word's position was coded with respect to the word that distinguishes the amb.Gap condition from the amb.noGap condition. These two coding schemes are illustrated in Table 1. Note that it was necessary to code word positions in both ways because the number of words separating these two positions was not constant across items, as it varied between one word in the case of verbs without an auxiliary (like che fare, 'what to do') and two words in the case of verbs introduced by an 
auxiliary (like che hai fatto, 'what you have done').

\begin{tabular}{|c|c|c|c|c|c|c|c|c|c|}
\hline Analysis 1 & -4 & -3 & -2 & -1 & 0 & +1 & +2 & +3 & +4 \\
\hline amb.noGap & Gli & studenti & hanno & capito & che & fare & gli & esami & è difficile \\
\hline amb.Gap & Gli & studenti & hanno & capito & che & fare & agli & esami & difficili \\
\hline unamb.Gap & Gli & studenti & hanno & chiesto & che & fare & agli & esami & difficili \\
\hline Analysis 2 & -6 & -5 & -4 & -3 & -2 & -1 & 0 & 1 & 2 \\
\hline amb.noGap & Gli & studenti & hanno & capito & che & fare & gli & esami & è difficile \\
\hline amb.Gap & Gli & studenti & hanno & capito & che & fare & agli & esami & difficili \\
\hline unamb.Gap & Gli & studenti & hanno & chiesto & che & fare & agli & esami & difficili \\
\hline
\end{tabular}

Table 1. Labelling of the regions for the two analyses of the experimental sentences in the Italian self-paced reading study.

Reading times are shown in Figure 2, presented as residuals from a linear model with word length as the sole predictor. The top panel illustrates that reading of the unamb.Gap condition shows dramatic slowing, compared to both of the other conditions, starting on the word immediately after che. Only in this condition is the indirect question analysis required at this point. The two ambiguous conditions are identical at this point, and do not differ until later; they begin to differ only at the point at which the indirect question analysis is required in the amb.Gap condition. 

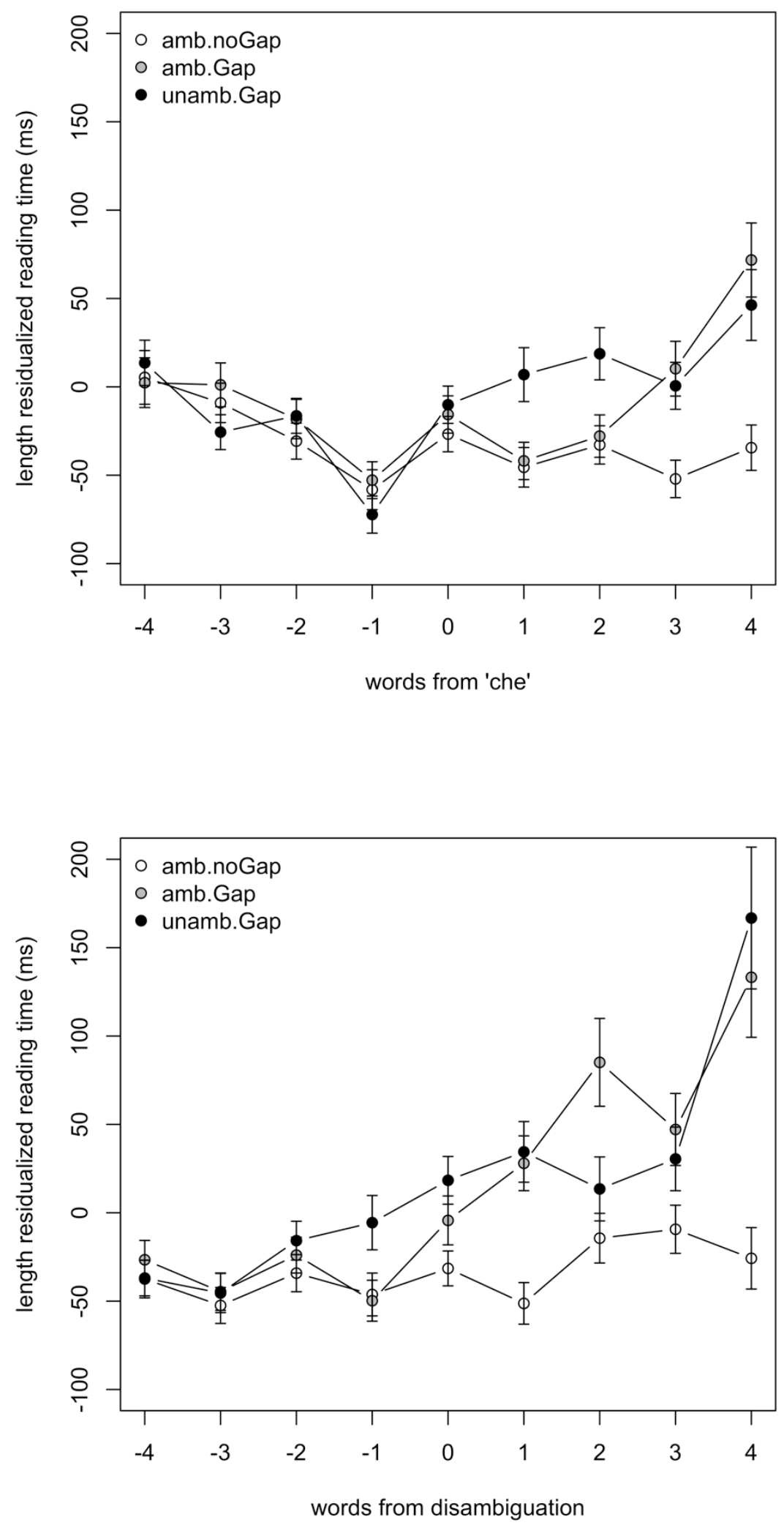
Figure 2. Mean length-residualized reading time (and SE) for each word, with word position coded relative to the position of che (top), and relative to the position of the disambiguating word (bottom).

RTs were analyzed with the lmer() function in $\mathrm{R}$ by means of the lmer.test $\mathrm{R}$ package (Kuznetsova, Brockhoff, \& Christensen 2017), including subjects and items as random factors (by adding random slopes the models failed to converge). Models of log-transformed reading times show identical patterns as raw times, so we report models of raw times for ease of interpretation. Again, we used treatment contrasts with the amb.Gap condition as the reference level. Word length was included in all models as a fixed effect.

We first ran models at each word position coded relative to che. In this analysis, the unamb.Gap condition showed inflated reading times relative to the amb.Gap condition beginning on the word following che (Estimate $=48.826, \mathrm{SE}=11.906 t=4.101 p<.001)$, and continuing on the next word $($ Estimate $=46.593, \mathrm{SE}=13.215, t=3.526, p<.001)$. The amb.noGap condition, as expected, showed no difference from the amb.Gap condition to this point ( $p s>.5)$. Turning to the analysis in which each word's position is coded relative to the disambiguation point, we see a significant difference between the amb.Gap condition and the amb.noGap condition emerging on the disambiguating word itself (i.e., position 0 in the lower panel of Figure 2; Estimate $=-27.202$, $\mathrm{SE}=12.932, t=-2.103, p=0.036)$ with this difference becoming very pronounced on the next word $($ Estimate $=-78.728, \mathrm{SE}=16.583, t=-4.747, p<.001)$.

\subsection{Discussion}

The results of the self-paced reading experiment corroborate the findings of the acceptability judgment task. In the amb.Gap condition, difficulty appears where it is expected, namely at the 
point at which the declarative analysis is ruled out. Therefore, in this respect the self-paced reading results strongly confirm the hypothesis that the declarative analysis is initially adopted in preference to the embedded question analysis, which would require positing a downstream gap. This finding is fully compatible with the first clause of the Minimal Chain Principle.

However, the self-paced reading experiment also confirms that the unamb.Gap condition elicits some difficulty. Importantly, the difficulty elicited by unamb.Gap condition appears at an earlier point of incremental processing (immediately after the word che) than the difficulty elicited by amb.Gap condition (when the gap is identified). A possibility is that this difficulty with the unamb.Gap condition has to do with the choice between the elliptical variant (che) and the full variant (che $\cos a)$ : readers expect the word $\cos a$ instead of the word fare and this explains the inflated reading times on the latter. Another explanation builds on the same parsing heuristic discussed above to account for the difference between the amb.noGap and the amb.Gap conditions. Remember that this unamb.Gap condition is not entirely unambiguous: as a matter of fact, the verb that precedes che in the unamb.Gap also admits for a continuation that does not involve a filler-gap dependency (cf. 14 and 15 above). This continuation is excluded immediately after the word che, namely at the point in which readers slow down. We conjecture that this reflects the cost of recognizing a movement dependency.

In conclusion, although the results clearly point in the direction of an explanatory role for the first clause of the Minimal Chain Principle, we do acknowledge that the issues just discussed make the contrast between the unamb.Gap and the amb.Gap conditions somewhat less sharp than expected. To address this issue, we followed up these experiments by testing a similar contrast in French. 


\section{Experiment 3. Gaps after ce que in French: Acceptability judgments}

The third experiment is an acceptability judgment task conducted in French, in which we compared sentences introduced by ce que that involve a filler-gap dependency, like (10b), with sentences that do not, like (10a). In order to assess the impact of the initial availability of a declarative complement clause analysis of (10b), we manipulated the type of verb selecting ce que, so as to compare ambiguous fragments, like (10b), with unambiguous fragments that could only be continued with a free relative, like (12). We expected a garden-path effect and subsequent reanalysis only in those cases in which the verb is ambiguous and can be followed by a declarative complement clause that does not involve a filler-gap dependency. We expected lower acceptability ratings for these sentences compared to sentences in which the ambiguity is resolved with the declarative clause analysis, and sentences containing a free relative, but where the ambiguity does not arise.

\subsection{Methods}

\subsubsection{Participants}

Seventy adult French participants volunteered to participate after being recruited via the RISC (Relais d'Information en Sciences de la Cognition). They were between 18 and 73 years of age $($ Mean $=27)$.

\subsubsection{Materials}

As for the Italian experiment, the questionnaire comprised 24 experimental items ${ }^{3}$ rotated

\footnotetext{
${ }^{3}$ One experimental item was removed from analysis because of a mistake in the script.
} 
through the 3 experimental conditions described above and repeated in (16) for convenience, so that each participant judged 8 experimental items per condition in total, one for each triplet, and 24 filler items of the same type as the Italian Experiment (see Appendix B). The filler and experimental materials were intermixed in an individually randomized order for each participant and were presented after 3 practice items. Henceforth we refer to the three experimental conditions as amb.noGap, amb.Gap, and unamb.Gap.

(18) a. Yasmina s'habitue à ce que sa mère regarde la télé chaque matin. (amb.noGap)

'Y. gets used to the fact that her mother watches TV every morning'

b. Yasmina s'habitue à ce que sa mère regarde à la télé chaque matin. (amb.Gap)

'Y. gets used to what her mother watches on TV every morning'

c. Yasmina voit ce que sa mère regarde à la télé chaque matin. (unamb.Gap)

'Y. sees what her mother watches on TV every morning'

As detailed above, the ce que in amb.noGap sentences introduces a declarative complement clause, while it introduces a free relative in the other conditions; the verb before ce que in the unamb.Gap condition does not allow for a complement clause continuation.

Each sentence appeared in the center of the screen and participants were asked to judge it on a 10 point Likert scale in which 0 meant "not natural at all" and 10 meant "perfectly natural". 4 As in the Italian version of the experiment, participants were instructed not to judge the content of the sentences, but only to pay attention to their "form". They were also explicitly told not to rely

\footnotetext{
4 The use of an 11-point (0 to 10) scale for French follows standard practice in many educational contexts in France (e.g. Dobrovie-Sorin, Ellsiepen, \& Hemforth 2016: 85). In any event, the use of different numbers of points on Likert scales does not appear to have serious consequences (e.g., Dawes 2008; Norman 2010).
} 
on grammatical rules learned at school, but simply to judge the sentences on the basis of how natural they sounded to them as speakers of French. The experiment was implemented and administered on-line on Ibex farm (Drummond, 2013) and lasted approximately 15 minutes.

\subsection{Results}

Figure 3 presents the results. The highest ratings were given to the unamb.Gap condition $($ Mean $=7.93)$, followed by the amb.noGap condition $($ Mean $=6.54)$ and the amb.Gap condition $($ Mean $=5.98)$. With regard to the fillers, fully grammatical sentences were rated high $($ Mean $=$ 7.64), while ungrammatical ones were rated very low (Mean $=2.25)$, as expected.

As for the Italian acceptability judgment data, we implemented a mixed-effects ordinal regression model with a logit link function, again using treatment contrasts with the amb.Gap condition as the reference level. The maximal model that converged included condition as a fixed effect, random intercepts for subject and items, and random slopes for subjects. The analysis revealed ratings to be significantly higher in the amb.noGap condition than in the amb.Gap condition (Estimate $=0.3384, \mathrm{SE}=0.1236, z=2.738, p=<.01)$ and also significantly higher in the unamb.Gap condition than in the amb.Gap condition (Estimate $=1.1976, \mathrm{SE}=0.1188, z$ $=10.079, p<.0001)$. 

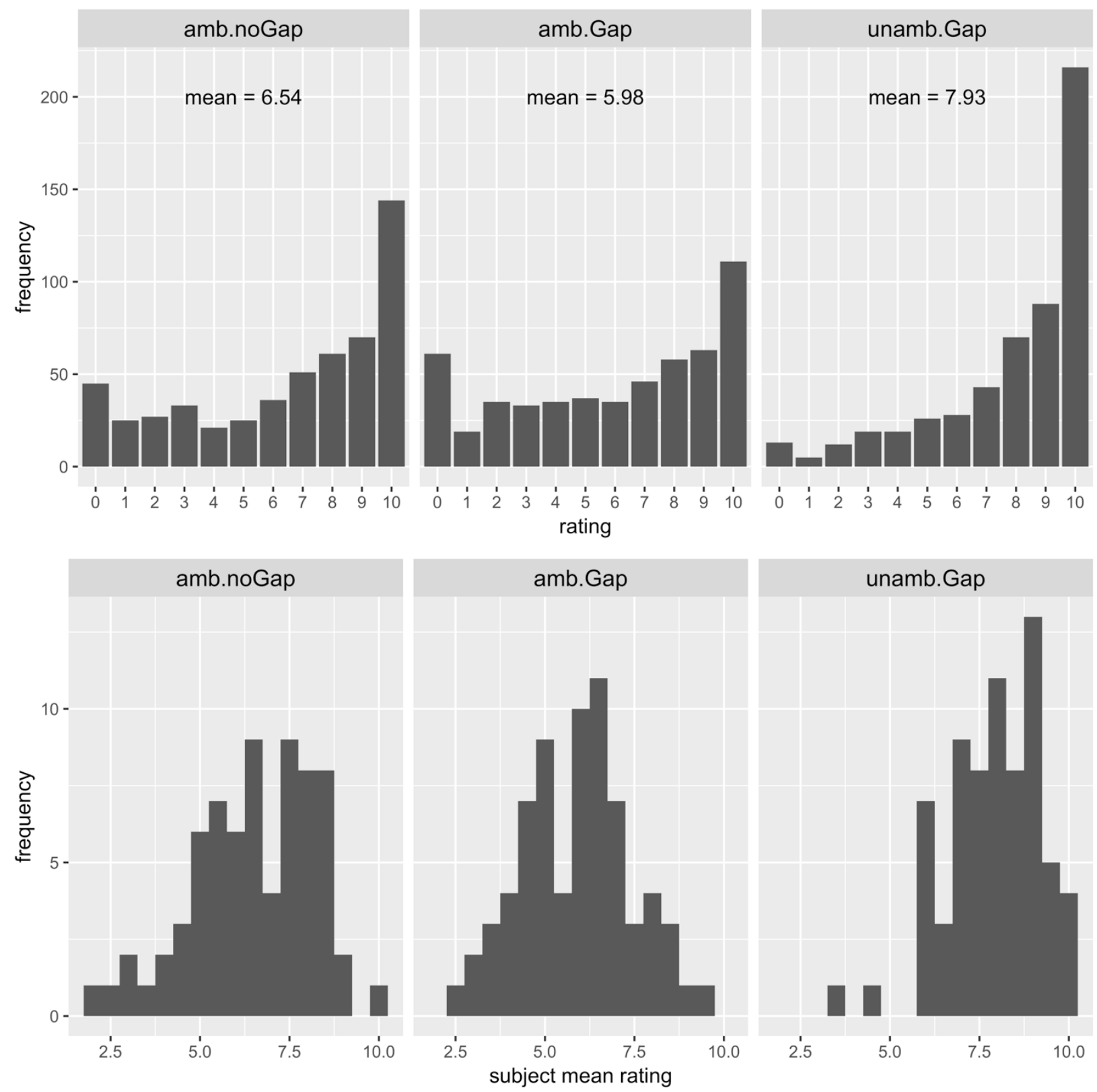

Figure 3. Results of French acceptability judgment study. Top panels show distributions of individual ratings in each condition, and bottom panels show distributions of subject means.

Despite the significant difference between the amb.noGap and amb.Gap conditions, it is notable that ratings in the amb.noGap condition are not nearly as high as in the unamb.Gap condition, and a follow-up analysis with the amb.noGap condition as reference level confirmed 
that these conditions did significantly differ (Estimate $=0.8592, \mathrm{SE}=0.1179, z=7.28, p<.0001)$. Moreover, if our initial statistical model is modified to use random item slopes for condition, rather than random subject slopes (note that a model with both sets of random slopes does not converge), the difference between amb.noGap and amb.Gap is not significant (Estimate $=0.4145, \mathrm{SE}=$ $0.5497, z=0.754, p=.45)$.

Further inspection of the data revealed an explanation for this pattern. Items using one of the eight verbs, se soucier de (to worry about), showed a difference in ratings between the amb.noGap condition and the amb.Gap condition of over five points in the opposite direction from the general trend. Items with this verb received a mean rating of 3.04 in the amb.noGap condition, the lowest of any verb, but 8.39 in the amb.Gap condition, the highest of any verb. When these items are excluded, the mean in the amb.noGap condition increases to 7.06 , and the mean in the amb.Gap condition decreases to 5.61. The reversed ratings in items using se soucier de raise the possibility that the declarative complement is not, in fact, fully acceptable with this verb; this would explain why these items receive low ratings in the amb.noGap condition, but also why they receive high ratings in the amb.Gap condition, as for this verb the putative garden path would not arise. Effectively, this verb would function like a verb in the unamb.Gap condition, where the declarative complement analysis is never entertained.

A follow-up analysis provides support for this conjecture. We undertook a corpus search on the FrWaC, a corpus of French on the Web (Baroni et al 2009), analyzing the continuations for each of the eight ambiguous verbs used in our study. For 's'habituer à ce que', the search returned only 7 results; for 'se soucier de ce que', 46 results; and for 'être attentive à ce que', 183 results. For the other verbs, there were many more instances, so we analyzed only the 200 first results. In Table 2, we show in how many of these cases the verb occurred with a declarative complement continuation as opposed to an RC continuation, and the difference in mean ratings for each verb, 
in the present study, between the amb.noGap and amb.Gap conditions. While most other verbs occur with a declarative complement much more than with a relative clause, se soucier de is an extreme outlier, occuring with a declarative complement in only 3 of 46 cases (7\%).

$$
\begin{gathered}
\text { Proportion CC (Total) } \quad \text { Rating Difference (amb.noGap - } \\
\text { amb.Gap }
\end{gathered}
$$

\begin{tabular}{l|cc}
\hline Veiller à ce que & $1(200)$ & 3.8 \\
Tenir à ce que & $.99(200)$ & 5.06 \\
Venir de ce que & $.95(200)$ & -1.53 \\
\hline S'habituer à ce que & $1(7)$ & 2.04 \\
\hline Se soucier de ce que & $.07(46)$ & -5.35 \\
\hline Être attentif à ce que & $.72(183)$ & -1.3 \\
\hline S'opposer à ce que & $.99(200)$ & 3.67 \\
\hline Faire attention à ce que & $.45(200)$ & -1.2 \\
\hline
\end{tabular}

Table 2. Proportion of CCs in the FrWaC for each of the eight ambiguous verbs used in our study, and difference in mean acceptability rating in the two critical conditions.

As for the Italian data, we undertook an analysis to assess whether there is a reliable relationship between a verb's ratings in the amb.Gap and amb.noGap condition (when se soucier de, which is an outlier in all respects, is excluded). We note that because only seven verbs are included, this correlational analysis has much less power than in the Italian study. The correlation did not reach significance $(p=.20)$, but was nevertheless substantial $(r=-.55)$. Thus, we cannot 
rule out the possibility that there are verb-specific biases that modulate the strength of the garden path effect. It does appear that some verbs, which receive high ratings when occuring with a declarative complement, induce a strong garden path effect, while other verbs induce little garden path effect, or even a reversed effect. In the aggregate, however, a garden path effect is in evidence.

\subsection{Discussion}

The French data show that participants give low ratings to sentences containing a filler-gap dependency only when there is a temporary ambiguity between the ultimately correct analysis and an alternative analysis that does not involve a gap. The amb.Gap condition received lower ratings than both the amb.noGap and unamb.Gap conditions. While the difference between the amb.Gap and unamb.Gap conditions is not as robust as we anticipated, it appears to have been weakened by the inclusion of one verb, se soucier de, that may not be fully acceptable with a declarative complement.

\section{Experiment 4. Gaps after ce que in French: Self-paced reading}

The fourth and last experiment is a self-paced reading study conducted on a separate group of French participants using the same materials used in the acceptability judgment task. This experiment allows for a precise localization of the point in incremental where the difficulty of the amb.Gap condition arises. 
7.1 Method

\subsubsection{Participants}

A separate group of 33 French adults participated in this study. Most were students in Paris. They were aged between 18 and 39 years old $($ Mean $=22.0)$.

\subsubsection{Materials and procedure}

We used the same French materials used for Experiment 3. The experiment was implemented and administered on Ibex Farm. Participants were tested in a quiet room at the DELETED FOR ANONYMITY. They were asked to read sentences word by word. Similarly to the Italian version of the experiment, participants had to press the spacebar in order to make the following word appear on the screen. Their reading times were automatically registered in milliseconds. In order to check that they were paying close attention to what they had to read and that they understood what they were reading, we created comprehension questions (yes-no questions), which appeared for one in three experimental items and for the grammatical fillers. These comprehension questions were the same for all the conditions of one single item and they focused on the embedded clause. One participant was excluded from subsequent analyses because his accuracy in answering these comprehension questions was below $80 \%$.

\subsection{Results}

For the analysis, each word was coded relative to the point of disambiguation, as shown in Table 2. The point of disambiguation was always immediately after the embedded verb; if a determiner appears just after the embedded verb, it means that there is no gap, so the continuation is unequivocally a declarative complement clause, while if a preposition appears just after the 
embedded verb, it means that there is a gap in the position of the object, so the continuation turns out to be a relative clause. Note that the most meaningful regions for analysis are at 0 and +1 ; in many items, as in the example in Table 2, the amb.Gap and unamb.Gap sentences end at the word in position +2 , and as a result any inference from reading time differences at this position is uncertain.

\begin{tabular}{|c|c|c|c|c|c|c|c|c|c|c|c|c|c|c|}
\hline Condition & -8 & -7 & -6 & -5 & -4 & -3 & -2 & -1 & 0 & +1 & +2 & +3 & +4 \\
\hline amb.noGap & Léo & tient & à & ce & que & sa & soeur & offre un & cadeau & à & leur mère. \\
\hline amb.Gap & Léo & tient & à & ce & que & sa & soeur offre & à & leur & mère. & & \\
\hline unamb.Gap & & Léo & apprécie & ce & que & sa & soeur offre & à & leur & mère. & & \\
\hline
\end{tabular}

Table 3. Labelling of the regions for the analysis of the experimental sentences in the French selfpaced reading study.

Mean length-residualized RTs for the regions of interests are plotted in Figure 5. Reading times for the conditions begin to separate one word after the disambiguation point, with the amb.Gap condition showing inflated reading times on this word. On the following word, reading times in the amb.Gap condition increase still more, while reading times in the unamb.Gap condition also start to increase. Notably, reading times in the amb.noGap condition remain low throughout.

The data were analyzed exactly as in the Italian self-paced reading experiment, again with the amb.Gap condition as the reference level. No differences between conditions approached significance until one word after disambiguation, at which point the amb.Gap reading times were longer than both the amb.noGap reading times (Estimate $=-83.768, \mathrm{SE}=39.875, t=-2.101, p=$ 
.036 ) and the unamb.Gap reading times (Estimate $=-63.854, \mathrm{SE}=30.771, t=-2.075, p=.038$ ). Even larger differences were observed on the next word between amb.Gap and amb.noGap $($ Estimate $=-192.15, \mathrm{SE}=49.62, t=-3.873, p<.001)$ and between amb.Gap and unamb.Gap (Estimate $=-110.93, \mathrm{SE}=48.45, t=-2.289, p=.022$ ). A follow-up analysis with amb.noGap as the reference level did not find significant differences between this condition and the unamb.Gap condition $(p s>.10)$, despite the trend evident in Figure 4. We reiterate, however, that it is probably not appropriate in any case to compare the two Gap conditions to the noGap condition at this word.

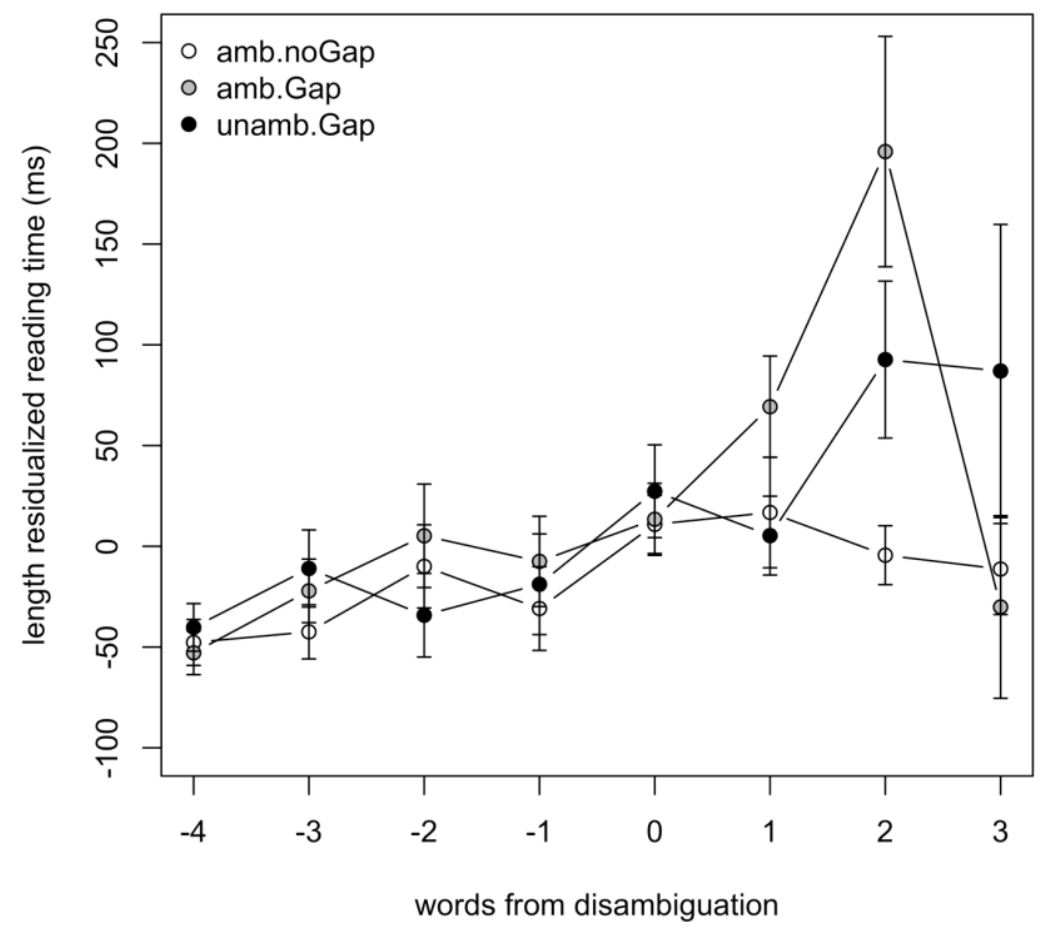

Figure 4. Mean length-residualized reading time (and SE) for each word, with word position coded relative to the position of the disambiguating word.

\subsection{Discussion}

The results of the self-paced reading experiment in French confirm the finding that the 
amb.Gap condition is difficult compared to the other two conditions, and illustrate that in the course of incremental processing, the difficulty arises immediately after the point at which an ambiguous string is revealed to be a free relative structure. In the acceptability judgment task, we also found reduced ratings in the amb.noGap condition compared to the unamb.Gap condition. However, there was no hint of difficulty in the amb.noGap condition in the self-paced reading study. In short, the French self-paced reading results provide complete confirmation of the prediction that readers do initially adopt the complement clause analysis, and experience difficulty if the correct analysis turns out to involve a free relative.

\section{General Discussion and conclusion}

In two acceptability judgment experiments, we showed that Italian and French participants tend to rate sentences that involve a filler-gap dependency lower than sentences involving the same lexical material but no filler-gap dependency; we also showed that this effect is modulated by the availability of an alternative parse up to a certain point, and it does not (solely) depend on sentence complexity. We argue that this decrement in acceptability is the effect of a garden path that arises during incremental processing, as a consequence of a general parsing strategy of gap-avoidance. We interpret these findings as evidence for the first clause of the Minimal Chain Principle, according to which filler-gap dependencies should not be posited except when necessary. This conclusion is corroborated by the results of two self-paced reading experiments, in which Italian and French participants showed a slowdown when an indirect question continuation is revealed after a verb that allows for a continuation with no filler-gap dependency.

One issue is whether the results can be explained in terms of frequency. We devoted a previous paper (Staub et al. 2018) to investigating the respective roles of frequency biases and 
structural factors in parsing of structures that are temporarily ambiguous between a complementation structure and a structure involving a filler-gap dependency. In that paper, we concluded, based on a series of experiments, that the role of structural factors is substantial while the role of lexical biases is negligible.

Nonetheless, we acknowledge that the frequency with which these constructions are used, either with specific verbs or in general, might contribute to the difficulty of the filler-gap dependency. In Italian, a preference to parse che as a complementizer rather than as a fronted $w h$ word might be due to a more frequent use of che as a complementizer. As noted above, we have not systematically evaluated the frequency of che as a fronted wh-word or a complementizer. Assuming that che is more frequent as a complementizer, this bias might explain why the amb.noGap condition is easier than the amb.Gap condition. However, this simple frequencybased explanation cannot easily explain the difference between the amb.Gap condition and the unamb.Gap conditions, as che is a fronted wh-word in both. Moreover, the variability in the ratings of the Italian amb.noGap condition is not reliably predicted by the corresponding amb.Gap condition, in which the same verb is used. We can thus conclude that a verb-specific preference towards a continuation is not the main factor that modulates the preferences observed in the Italian acceptability judgment task. In the French acceptability judgment task, we found a clearer relationship (though still not a significant one, due to the small number of verbs) between ratings in the amb.noGap and amb.Gap conditions: A verb that elicited high ratings in one condition elicited low ratings in the other. Thus, it is indeed possible that verb-specific preferences toward one continuation or the other play a role here. But at the same time, both sets of self-paced reading results show strong effects that are consistent with a garden path that emerges as predicted by the Minimal Chain Principle; in the remainder of this discussion, we assume that these results are explained by that principle. 
In principle, these results, in addition to being interesting for their psycholinguistic implications, may be relevant for syntactic theory too. The Minimalist program inaugurated in the 1990s (Chomsky 1995) puts notions such as efficiency of computation and global economy at the centre of the factors driving grammar. Any finding concerning processing thus becomes in principle directly relevant under this view. Oddly enough, while the appeal to computational efficiency (including minimizing short-term memory burden) is one of the explicit motivations behind the Minimalist program, few attempts have been made to bridge the gap between minimalist syntax and the psycholinguistic studies that share a similar agenda.

Filler-gap dependencies are certainly one place where such a bridge can in principle be built. The status of long-distance dependencies and of the rules responsible for their formation have changed in the last decades of syntactic theorizing. In GB Theory, Move, a transformation operating on syntactic structures, was literally responsible for displacement. Its cost was easily and transparently derived from the fact that Move implies a modification of pre-existing structures. The copy theory approach introduced in early Minimalism (cf. Chomsky 1995), instead made the "stigmatization" of movement somewhat less straightforward, as under this theory "displacement" is the by-product of a special application of the Merge operation, which is also responsible for structure building. Still, early Minimalism maintained such a stigma by labelling movement a "radical imperfection," dispreferred over Merge during syntactic derivations. This was achieved by a Principle: "Merge over Move" (MOM: Chomsky 1998).

The status of MOM has been deeply criticized, on both empirical and conceptual grounds in subsequent years (see among others Castillo, Drury \& Grohmann 1999; Deal 2009; Hornstein 2009; Shima 2000). In recent developments of the theory, the only difference between Move and Merge is that the former merges a category taken from the existing tree while the latter merges an 
element taken from the numeration. There is thus no obvious way to order Merge and Move in terms of the complexity of the operation involved.

What do our empirical results add to the existing theoretical debate? Consider again the minimal pair used in our experimental studies in Italian, repeated below for convenience.

(19) a. Gli studenti hanno capito che fare gli esami è difficile.

'The students understood that taking exams is difficult'

b. Gli studenti hanno capito che fare agli esami difficili.

'The students understood what to do for difficult exams'

(19a) implies Merge of che while (19b) implies Move of che. The garden path effect observed in (b) indicates that when the parser has a choice it chooses Merge over Move.

Can this result be considered as a processing foundation for MOM? There are reasons to be sceptical. We suspect that what is costly is not the operation Move per se, but the processing of the long-distance dependency that is associated to it. This cost does not necessarily imply that there is an ontological difference between Merge and Move, nor that they are ordered by any economy principle. In particular, the long-distance dependencies in our experiments require the search for a gap and the maintenance of the filler in the memory buffer. Which of these components is costly remains to be seen. One way to investigate this issue would be looking at long-distance dependencies that do not involve a gap (like long distance agreement or anaphora resolution), or at movement dependencies that are very local, like passives. An experimental implementation of such questions remains open to further investigation.

To conclude, our results provide further evidence for a structural parsing principle of gap avoidance, extending Staub's et al. conclusions. They also extend those previous results, offering 
more compelling evidence in favour of the first clause of the Minimal Chain Principle. We do not think that these findings can be taken as a processing foundation for a grammatical principle in which Merge overrides Move (MOM). They can rather be interpreted as evidence that the preference of Merge over Move arises at the level of processing and does not belong to grammar. This conclusion is consistent with the view of a bare bone syntax, where Merge and Move are just instances of the same basic operation.

\section{References.}

Adger, D. 2013. A syntax of substance. Cambridge, A.: MIT Press.

Arsenijević, B. 2009. Clausal complementation as relativization. Lingua,119: 39-50.

Baroni, M. et al. 2009. The Wacky wide web: a collection of very large linguistically processed web-crawled corpora. In: Language resources and evaluation 43.3: 209-226.

Castillo, J. C., J. Drury, \& Grohmann, K. 1999. Merge over Move and the Extended Projection Principle. University of Maryland Working Papers in Linguistics 8, 63-103.

Cecchetto, C., \& Donati, C. 2015. (Re)Labeling. Cambridge, MA.: MIT Press.

Chomsky, N. 1998. Minimalist inquiries: The framework. MIT Occasional Papers in Linguistics 15. Cambridge: MIT Press (MITWPL).

Chomsky, N. 2000. Minimalist Inquiries: the framework. In R. Martin, D. Micheals and J. Uriagereka (eds.), Step by step: Essays on Minimalist syntax in honour of Howard Lasnik, 91-155. Cambridge: MIT Press.

Chomsky, N. 2004. Beyond Explanatory Adequacy. In A. Belleti (ed.), Structures and Beyond: the cartography of syntactic structures (Vol. 3), 104-131. New York, NY: OUP. 
Clifton, C., \& Frazier, L. 1989. Comprehending sentences with long-distance dependencies. In Linguistic structure in language processing, 273-317. Dordrecht: Springer.

Dawes, J. 2008. 'Do Data Characteristics Change According to the Number of Points Used? An Experiment Using 5-point, 7-point and 10-point Scales. International Journal of Market Research, 50:61-77.

Deal, A. R. 2009. The origin and content of expletives: evidence from 'selection.' Syntax 12:3: 285-323.

De Cuba, C. 2017. Noun complement clauses as referential modifiers. Glossa 2(1): 1-46.

De Vincenzi, M. 1991. Syntactic parsing strategies in Italian: the Minimal Chain Principle. Dordrecht: Kluwer.

Drummond, A. 2013. Ibex farm. Online server: http://spellout. net/ibexfarm.

Fodor, J. 1978. Parsing strategies and constraints on transformations. Linguistic Inquiry, 9(3), 427473.

Hornstein, N. 2009. A Theory of Syntax: Minimal Operations and Universal Grammar. New York, NY: CUP.

Kayne, R. 2008. Why isn't this a complementizer? In Comparisons and Contrasts, 190-227. New York: Oxford University Press.

Konrad, I. 2019a. Quand la nominalization envahit la subordination-étude sur 'ce que’ dans les propositions subordonnées en français, selon une approche comparative, diachronique et expérimentale. Unpublished Doctoral Dissertation, University Paris Diderot.

Konrad, I. 2019b. At the crossroads between (semi-)free relatives and indirect questions in French. In: I. Feldhausen, M. Elsig, I. Kuchenbrandt and M. Neuhaus (eds.), Romance Languages and Linguistic Theory 15 - Selected papers from 'Going Romance’ 30, Frankfurt, 74-91. John Benjamins Publishing Company. 
Kratzer, A. 2006. Severing the external argument from its verb. In: J. Rooryck and L. Zaring (eds.), Phrase structure and its lexicon, 109-137. Dordrecht: Kluwer.

Kuznetsova A., Brockhoff P., \& Christensen R. H. B. 2017. ImerTest Package: Tests in Linear Mixed Effects Models. Journal of Statistical Software, 82(13), 1-26.

Manzini, M. R., \& Savoia, L. M. 2003. The nature of complementizers. Rivista di Grammatica Generativa 28: 87-110.

Norman, G. 2010. Likert scales, levels of measurement and the "laws" of statistics. Advances in health sciences education, 15(5), 625-632.

Rizzi, L. 2019. Che and weak islands. In Franco L and D. Lorusso (eds), Linguistic Variation: Structure and Interpretation, Berlin: De Gruyter.

Traxler, M. J., \& Pickering, M. J. 1996. Plausibility and the processing of unbounded dependencies: An eye-tracking study. Journal of Memory and Language, 35, 454-475.

Shima, E. 2000. A preference for move over merge. Linguistic Inquiry 31:2, 375-385.

Staub, A., Foppolo, F., Donati, C., \& Cecchetto, C. 2018. Relative clause avoidance: evidence for a structural parsing principle. Journal of Memory and Language, 98, 26-44.

Stowe, L. A. 1986. Parsing WH-constructions: Evidence for on-line gap location. Language and cognitive processes, 1(3), 227-245.

Stowell, T. 1981. Origins of Phrase structure. Doctoral dissertation, MIT.

\section{APPENDIX A}

List of experimental materials used in Italian experiments 1 and 2 (the region of disambiguation for each sentence is underlined) 
1.a - Gli studenti hanno capito che fare gli esami è difficili

The students understood that taking exams is difficult.

1.b - Gli studenti hanno capito che fare agli esami difficili.

The students understood what to do during difficult exams.

1.c - Gli studenti hanno chiesto che fare agli esami difficili.

The students asked what to do during difficult exams.

2.a - I tuoi amici hanno scoperto che hai fatto una festa.

Your friends found out that you had a party.

2.b - I tuoi amici hanno scoperto che hai fatto alla festa.

Your friends found out what you did at the party.

2.c - I tuoi amici vogliono sapere che hai fatto alla festa.

Your friends want to know what you did at the party.

3.a - Il mio vicino mi ha spiegato che regalare un cagnolino è un gesto affettuoso.

My neighbor explained to me that giving a puppy away is a tender gesture.

3.b - Il mio vicino mi ha spiegato che regalare a un cagnolino molto affettuoso.

My neighbor explained to me what to give away to a very tender puppy.

3.c - Il mio vicino mi ha consigliato che regalare a un cagnolino molto affettuoso.

My neighbor suggested to me what to give away to a very tender puppy.

4.a - La guida ci ha suggerito che visitare le città francesi è più bello.

The guide advised us that visiting the French cities is more beautiful.

4.b - La guida ci ha suggerito che visitare nelle città francesi più belle.

The guide advised us what to visit in the most beautiful French cities.

4.c - La guida ci ha raccomandato che visitare nelle città francesi più belle. 
The guide recommended to us what to visit in the most beautiful French cities.

5.a - Mi hanno appena scritto che hai ricevuto un'offerta dalla banca.

They have just written to me that you have received an offer from the bank.

5.b - Mi hanno appena scritto che hai ricevuto come offerta dalla banca.

They have just written to me about what you have received as an offer from the bank.

5.c - Mi hanno appena chiesto che hai ricevuto come offerta dalla banca.

They have just asked to me about what you have received as an offer from the bank.

6.a - Per strada ti insegnano che vendere droga fa guadagnare soldi.

In the street they teach you that selling drugs makes you earn money.

6.b - Per strada ti insegnano che vendere come droga per guadagnare soldi.

In the street they teach you what drug to sell to make money.

6.c - Per strada ti consigliano che vendere come droga per guadagnare soldi.

In the street they suggest you what drug to sell to make money.

7.a - Ho scoperto che evitare alcuni quartieri è indicato nella guida.

I have found that avoiding some neighborhoods is indicated in the guide.

7.b - Ho scoperto che evitare in alcuni quartieri indicati nella guida.

I have found what to avoid in some neighborhoods indicated in the guide.

7.c - Ho domandato che evitare in alcuni quartieri indicati nella guida.

I have asked what to avoid in some neighborhoods indicated in the guide.

8. a - Mio padre mi ha chiarito che far firmare $\underline{1}$ notaio fa ottenere un rimborso.

My father made it clear to me that getting a notary sign gets you a refund.

8.b - Mio padre mi ha chiarito che far firmare al notaio per ottenere il rimborso.

My father made it clear to me what needs to be signed by a notary to get a refund. 
8.c - Mio padre mi ha consigliato che far firmare al notaio per ottenere il rimborso.

My father made it clear to me what needs to be signed by a notary to get a refund

9.a - Prima dell'incontro ignoravo che scrivere un contratto tutela i miei interessi.

Before the meeting, I ignored the fact that writing a contract protects my interests.

9.b - Prima dell'incontro ignoravo che scrivere nel contratto a tutela dei miei interessi.

Before the meeting, I ignored what to write in a contract to protect my interests.

9.c - Prima dell'incontro mi chiedevo che scrivere nel contratto a tutela dei miei interessi.

Before the meeting, I was wandering what to write in a contract to protect my interests.

10.a - Da anni ho appurato che consigliare gli studenti è una perdita di tempo.

For years I have known that advising students is a waste of time.

10.b - Da anni ho appurato che consigliare agli studenti per non perdere tempo.

For years I have known what to advise to the students to not waste time.

10.c - Da anni vorrei sapere che consigliare agli studenti per non perdere tempo.

For years I wondered what to advise to the students to not waste time.

11.a - Ho letto che hanno scritto un nuovo libro.

I've read that they wrote a new book.

11.b - Ho letto che hanno scritto nel nuovo libro.

I've read what they wrote in the new book.

11.c - Mi domando che hanno scritto nel nuovo libro.

I wonder what they wrote in the new book.

12.a - L'agenzia mi ha risposto che hanno mandato un altro pacco.

The agency told me that they have sent another package.

12.b - L'agenzia mi ha risposto che hanno mandato nell'altro pacco.

The agency told me what they have sent in the other package. 
12.c - L'agenzia mi ha elencato che hanno mandato nell'altro pacco.

The agency listed to me what they have sent in the other package.

13.a - L'autore ha rivelato che farà un nuovo spettacolo.

The author has revealed that he will do a new show.

13.b - L'autore ha rivelato che farà nel nuovo spettacolo.

The author has revealed what he will do in the new show.

13.c - L'autore si domanda che farà nel nuovo spettacolo.

The author is wondering what he will do in the new show.

14.a - Abbiamo finalmente deciso che prepareremo la cena di stasera.

We have finally decided that we will make the dinner tonight.

14.b - Abbiamo finalmente deciso che prepareremo per la cena di stasera.

We have finally decided what we will make for dinner tonight.

14.c - Ci hanno domandato che prepareremo per la cena di stasera.

They asked us what we will make for the dinner tonight.

15.a - Nel volantino non avete specificato che darete una ricompensa a chi se lo merita.

In the flyer you did not specify that you will give a reward to those who deserve it.

15.b - Nel volantino non avete specificato che darete come ricompensa a chi se lo merita.

In the flyer you did not specify what you will give as a reward to those who deserve it.

15.c - Nel volantino non avete elencato che darete come ricompensa a chi se lo merita.

In the flyer you did not list what you will give as a reward to those who deserve it.

16.a - Un collega mi ha comunicato che diffondere la sua versione è un dovere per un giornalista.

A colleague told me that spreading his own version is a duty for a journalist.

16.b - Un collega mi ha comunicato che diffondere della sua versione sui doveri di un giornalista. A colleague told me what to spread of his own version about the duties of a journalist. 
16.c - Un collega mi ha raccomandato che diffondere della sua versione sui doveri di un giornalista.

A colleague recommended what to spread of his own version about the duties of a journalist.

17.a - Emma ha subito intuito che hai preparato dei dolci per il suo compleanno.

Emma immediately sensed that you made some desserts for her birthday.

17.b - Emma ha subito intuito che hai preparato come dolci per il suo compleanno.

Emma immediately sensed what you made as desserts for her birthday.

17.c - Emma mi ha elencato che hai preparato come dolci per il suo compleanno.

Emma listed to me what you made as dessertsfor her birthday.

18. $\mathrm{a}$ - Ti avevamo chiarito che credere alla sua versione è poco razionale.

We made it clear to you that believing his version was not quite rational.

18.b - Ti avevamo chiarito che credere della sua versione poco razionale.

We made it clear to you what to believe of his not quite rational version.

18.c - Ti avevamo chiesto che credere della sua versione poco razionale.

We asked you what to believe of his not very rational version.

19.a - Tuo fratello mi ha detto che hai cambiato la bicicletta da corsa.

Your brother told me that you have changed your racing bike.

19.b - Tuo fratello mi ha detto che hai cambiato nella bicicletta da corsa.

Your brother told me what you have changed on your racing bike.

19.c - Tuo fratello vuole sapere che hai cambiato nella bicicletta da corsa.

Your brother wants to know what you have changed on your racing bike.

20.a - Il giornalista specifica che hanno distrutto l'accampamento militare.

The journalist specified that they have destroyed the military camp. 
20.b - Il giornalista specifica che hanno distrutto nell'accampamento militare.

The journalist specified what they have destroyed in the military camp.

20.c - Il giornalista si domanda che hanno distrutto nell'accampamento militare.

The journalist is wondering what they have destroyed in the military camp.

21.a - La mia collega mi ha detto che cucinare una cena vegana è semplice.

My colleague told me that cooking a vegan dinner is simple.

21.b - La mia collega mi ha detto che cucinare per una cena vegana semplice.

My colleague told me what to cook for a simple vegan dinner.

21.c - La mia collega mi ha consigliato che cucinare per una cena vegana semplice.

My colleague advised me what to cook for a simple vegan dinner.

22.a - Tommaso mi ha fatto vedere che avete comprato una nuova casa.

Tommaso show me that you have bought a new house.

22.b - Tommaso mi ha fatto vedere che avete comprato per la nuova casa.

Tommaso showed me what you have bought for the new house.

22.c - Tommaso mi ha chiesto che avete comprato per la nuova casa.

Tommaso asked me what you have bought for the new house.

23. a - Il reporter sa bene che fotografare $\underline{1}$ l confine è pericoloso.

The reporter knows very well that photographing the border is dangerous.

23.b - Il reporter sa bene che fotografare dal confine pericoloso.

The reporter knows very well what to photograph from the dangerous the border.

23.c - Il reporter si chiede che fotografare dal confine pericoloso.

The reporter is wondering what to photograph from the dangerous the border.

24.a - I genitori spesso sottovalutano che lasciare i figli può aiutarli. 
Parents often underestimate that leaving children can help them.

24.b - I genitori spesso sottovalutano che lasciare ai figli per aiutarli.

Parents often underestimate what to leave to their children to help them.

24.c - I genitori spesso si domandano che lasciare ai figli per aiutarli.

Parents often wonder what to leave to their children to help them.

\section{APPENDIX B}

List of experimental materials used in French experiments 3 and 4 (the region of disambiguation for each sentence is underlined)

1.a - Pierre veille à ce que Marie enregistre la photo sur son portable.

Pierre watches out for the fact that Mary registers the picture on her phone.

1.b - Pierre veille à ce que Marie enregistre sur son portable.

Pierre watches out for what Mary registers on her phone.

1.c - Pierre regarde ce que Marie enregistre sur son portable.

Pierre watches what Mary registers on her phone.

2.a - Léo tient à ce que sa sœur offre un cadeau à leur mère.

Léo cares for the fact that his sister gives a gift to their mother.

2.b - Léo tient à ce que sa sœur offre à leur mère.

Léo cares for what his sister offers to their mother.

2.c - Léo apprécie ce que sa sœur offre à leur mère.

Léo likes what his sister offers to their mother.

3.a - Paul fait attention à ce que sa femme regarde le film sur l'ordinateur. 
Paul takes care that his wife watches the movie on the computer.

3.b - Paul fait attention à ce que sa femme regarde sur l'ordinateur.

Paul takes care of what his wife watches on the computer.

3.c - Paul contrôle ce que sa femme regarde sur l'ordinateur.

Paul checks what his wife watches on the computer.

4.a - Julien s'oppose à ce que son patron organise une réunion pour le mois prochain.

Julien is opposed to the fact that his boss sets up a meeting for the next month.

4.b - Julien s'oppose à ce que son patron organise pour le mois prochain.

Julien is opposed to what his boss sets up a meeting for the next month.

4.c - Julien est contre ce que son patron organise pour le mois prochain.

Julien is against what his boss sets up for the next month.

5.a - Théo se soucie de ce que Pauline poste un nouveau statut sur Facebook.

Théo is worried about the fact that Pauline posts a new status on Facebook.

5.b - Théo se soucie de ce que Pauline poste sur Facebook.

Théo is worried about what Pauline posts on Facebook.

5.c - Théo suit ce que Pauline poste sur Facebook.

Théo follows what Pauline posts on Facebook.

6.a - Mickael est attentif à ce que son frère achète des aliments sains avant le marathon.

Mickael is careful to the fact that his brother buys healthy food before the marathon.

6.b - Mickael est attentif à ce que son frère achète avant le marathon.

Mickael is careful to what his brother buys before the marathon.

6.c - Mickael surveille ce que son frère achète avant le marathon.

Mickael oversees what his brother buys before the marathon.

7.a - Amélie s'habitue à ce que son père prépare des sushis pour le déjeuner. 
Amélie gets used to the fact that her father prepares sushis for lunch.

7.b - Amélie s'habitue à ce que son père prépare pour le déjeuner.

Amélie gets used to what her father prepares for lunch.

7.c - Amélie adore ce que son père prépare pour le déjeuner.

Amélie loves what her father prepares for lunch.

8.a - Le danger vient de ce que la pollution provoque un changement dans l'air des villes.

The danger lies in the fact that the pollution brings about a change in the urban air.

8.b - Le danger vient de ce que la pollution provoque dans l'air des villes.

The danger lies in what the pollution brings about in the urban air.

8.c - Le danger a pour origine ce que la pollution provoque dans l'air des villes.

The danger originates from what the pollution brings out in the urban air.

9.a - Luc veille à ce que Lou organise une surprise pour la fête.

Luc watches out for the fact that Lou organizes a surprise for the party.

9.b - Luc veille à ce que Lou organise pour la fête.

Luc watches out for what Lou organizes for the party.

9.c - Luc filme ce que Lou organise pour la fête.

Luc shoots what Lou organizes for the party.

10.a - Samuel tient à ce que Léa lui donne des livres pour le remercier.

Samuel cares for the fact that Léa gives him books to thank him.

10.b - Samuel tient à ce que Léa lui donne pour le remercier.

Samuel cares for what Léa gives him to thank him.

10.c - Samuel prend en photo ce que Léa lui donne pour le remercier.

Samuel takes pictures of what Léa gives him to thank him.

11.a - Rémi fait attention à ce que son père achète ses médicaments chaque semaine. 
Rémi takes care that his father buys his medicines every week.

11.b - Rémi fait attention à ce que son père achète chaque semaine.

Rémi takes care of what his father buys every week.

11.c - Rémi vérifie ce que son père achète chaque semaine.

Rémi checks what his father buys every week.

12.a - Le député s'oppose à ce que le gouvernement propose une nouvelle réforme au Parlement.

The MP is opposed to the fact that the government proposes a new reform at the Parliament.

12.b - Le député s’oppose à ce que le gouvernement propose au Parlement.

The MP is opposed to what the government proposes at the Parliament.

12.c - Le député approuve ce que le gouvernement propose au Parlement.

The MP approves what the government proposes at the Parliament.

13.a - Nicolas se soucie de ce que son ex femme garde des meubles dans la cave.

Nicolas is worried about the fact that his ex wife keeps furniture in the basement.

13.b - Nicolas se soucie de ce que son ex femme garde dans la cave.

Nicolas is worried about what his ex wife keeps in the basement.

13.c - Nicolas fait la liste de ce que son ex femme garde dans la cave.

Nicolas makes a list of what his ex wife keeps in the basement.

14.a - Marie est attentive à ce que sa sœur raconte une blague à chaque repas.

Marie is careful to the fact that her sister tells a joke at every meal.

14.b - Marie est attentive à ce que sa sœur raconte à chaque repas.

Marie is careful to what her sister tells at every meal.

14.c - Marie écoute ce que sa sœur raconte à chaque repas.

Marie listens to what her sister tells at every meal.

15.a - Jonas s'habitue à ce que son frère prépare un poisson d'avril tous les ans. 
Jonas gets used to the fact that his brother prepares an April fool every year.

15.b - Jonas s'habitue à ce que son frère prépare tous les ans.

Jonas gets used to what his brother prepares every year.

15.c - Jonas déteste ce que son frère prépare tous les ans.

Jonas hates what his brother prepares every year.

16.a - Le problème vient de ce que Samia réclame une augmentation pour le mois prochain.

The problem lies in the fact that Samia claims a salary increase for the next month.

16.b - Le problème vient de ce que Samia réclame pour le mois prochain.

The problem lies in what Samia claims for the next month.

16.c - Le problème concerne ce que Samia réclame pour le mois prochain.

The problem concerns what Samia claims for the next month.

17.a - Marc veille à ce que Julie raconte cette anecdote à sa mère.

Marc watches out for the fact that Julie tells an anecdote to her mother.

17.b - Marc veille à ce que Julie raconte à sa mère.

Marc watches out for what Julie tells to her mother.

17.c - Marc entend ce que Julie raconte à sa mère.

Marc hears what Julie tells to her mother.

18.a - Claire tient à ce que son frère lui achète un bijou pour son anniversaire.

Claire cares for the fact that her brother buys her a piece of jewelry for her birthday.

18.b - Claire tient à ce que son frère lui achète pour son anniversaire.

Claire cares for what her brother buys her for her birthday.

18.c - Claire revend ce que son frère lui achète pour son anniversaire.

Claire resells what her brother buys her for her birthday.

19.a - Pauline fait attention à ce que son mari nettoie les fenêtres dans la chambre. 
Pauline takes care that her husband cleans the windows in the bedroom.

19.b - Pauline fait attention à ce que son mari nettoie dans la chambre.

Pauline takes care of what her husband cleans in the bedroom.

19.c - Pauline salit ce que son mari nettoie dans la chambre.

Pauline dirties what her husband cleans in the bedroom.

20.a - Rémi s'oppose à ce que son enfant demande un ordinateur pour Noël.

Rémi is opposed to the fact that his child asks for a computer for Christmas.

20.b - Rémi s’oppose à ce que son enfant demande pour Noël.

Rémi is opposed to what his child asks for for Christmas.

20.c - Rémi mémorise ce que son enfant demande pour Noël.

Rémi memorizes what his child asks for for Christmas.

21.a - Lucile se soucie de ce que Gabriel cache un secret à sa femme.

Lucile is worried about the fact that Gabriel is hiding a secret to his wife.

21.b - Lucile se soucie de ce que Gabriel cache à sa femme.

Lucile is worried about what Gabriel is hiding to his wife.

21.c - Lucile est au courant de ce que Gabriel cache à sa femme.

Lucile is aware of what Gabriel is hiding to his wife.

22.a - Mike est attentif à ce que Jane réserve leurs billets pour Cuba.

Mike is careful to the fact that Jane books their plane tickets for Cuba.

22.b - Mike est attentif à ce que Jane réserve pour Cuba.

Mike is careful to what Jane books for Cuba.

22.c - Mike note ce que Jane réserve pour Cuba.

Mike writes down what Jane books for Cuba.

23.a - Yasmina s'habitue à ce que sa mère regarde la télévision chaque matin. 
Yasmina gets used to the fact that her mother watches TV every morning.

23.b - Yasmina s'habitue à ce que sa mère regarde chaque matin.

Yasmina gets used to what her mother watches every morning.

23.c - Yasmina voit ce que sa mère regarde chaque matin.

Yasmina sees what her mother watches every morning.

24.a - L'addiction vient de ce que la nicotine déclenche une stimulation dans le cerveau.

The addiction lies in the fact that the nicotine triggers a stimulation in the brain.

24.b - L’addiction vient de ce que la nicotine déclenche dans le cerveau.

The addiction lies in what the nicotine triggers in the brain.

24.c - L'addiction découle de ce que la nicotine déclenche dans le cerveau.

The addiction arises from what the nicotine triggers in the brain.

\section{APPENDIX C}

Figure 1. Average ratings for each ambiguous verb used in the Italian acceptability judgment task in the amb.Gap condition, plotted against average rating in the amb.noGap condition, with regression line. 


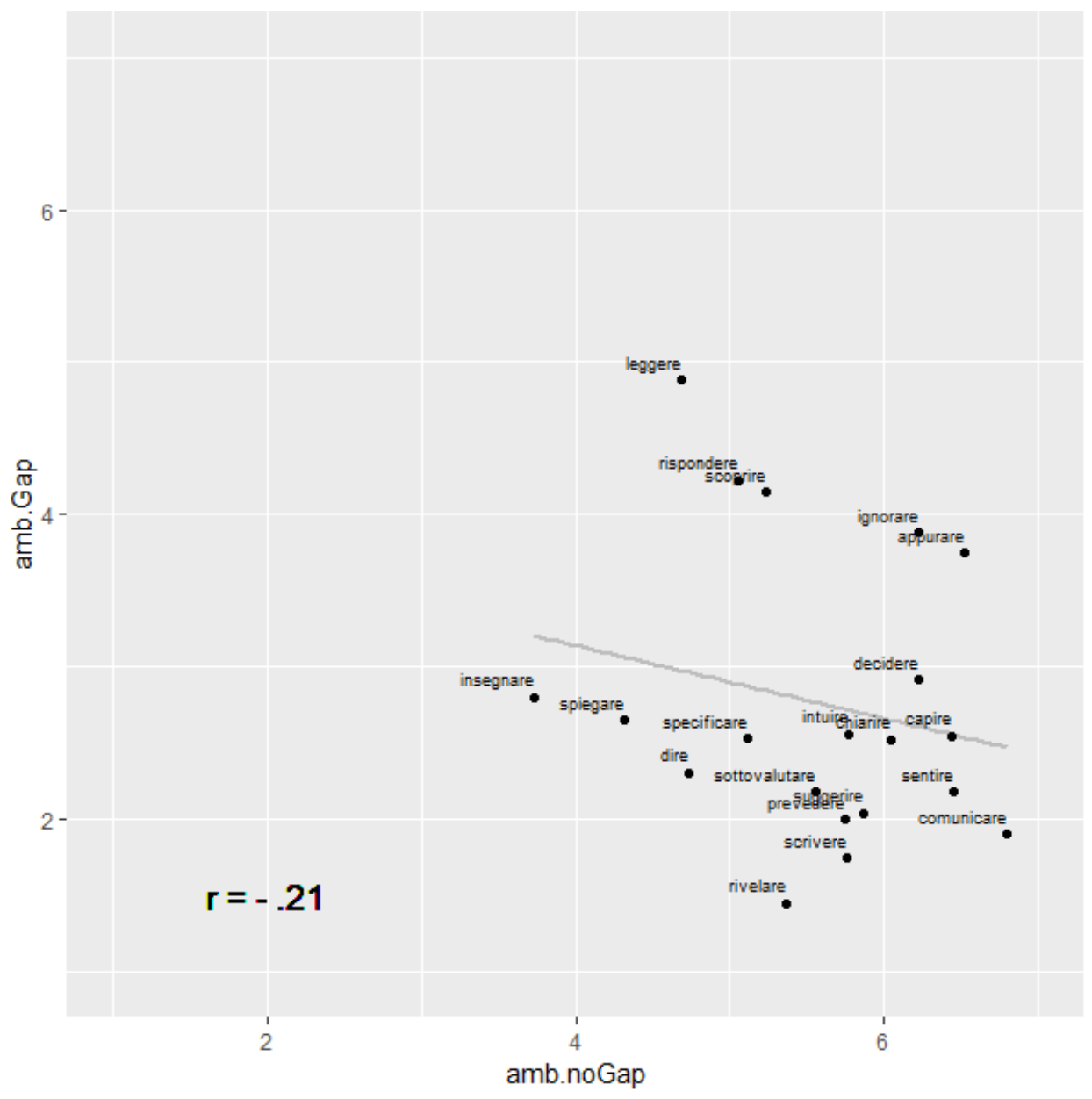

